REVIEW

\title{
Recent advances in radiological and radionuclide imaging and therapy of neuroendocrine tumours
}

\author{
Gregory Kaltsas, Andrea Rockall ${ }^{1}$, Dimitrios Papadogias, Rodney Reznek ${ }^{1}$ and Ashley B Grossman \\ Departments of Endocrinology and ${ }^{1}$ Academic Radiology, St Bartholomew's Hospital, London ECIA 7BE, UK \\ (Correspondence should be addressed to Ashley B Grossman, Department of Endocrinology, St Bartholomew's Hospital, London EC1A 7BE, UK; \\ Email: a.b.grossman@qmul.ac.uk)
}

\begin{abstract}
Neuroendocrine tumours (NETs) constitute a heterogeneous group of tumours that are able to express cell membrane neuroamine uptake mechanisms and/or specific receptors, such as somatostatin receptors, which can be of great value in the localization and treatment of these tumours. Scintigraphy with ${ }^{111}$ In-pentetreotide has become one of the most important imaging investigations in the initial identification and staging of gastro-enteropancreatic (GEP) tumours, whereas helical computed tomography (CT), magnetic resonance imaging (MRI), endoscopic and/or peri-operative ultrasonography are used for the precise localization of GEPs and in monitoring their response to treatment. Scintigraphy with ${ }^{123}$ I-MIBG (meta-iodobenzylguanidine) is sensitive in the identification of chromaffin cell tumours, although scintigraphy with ${ }^{111}$ In-pentetreotide may also have a role in the localization of malignant chromaffin cell tumours and medullary thyroid carcinoma; for further localization and monitoring of the response to treatment both CT and MRI are used with high diagnostic accuracy. More recently, positron emission tomography (PET) scanning is being increasingly used for the localization of NETs, particularly when other imaging modalities have failed, although its precise role and utility remain to be defined. Surgery is still the usual initial therapeutic, and only curative, modality of choice; however, the majority of NETs will require further treatment with somatostatin analogues and/or interferon; chemotherapy may be used for progressive and highly aggressive NETs, but its role has not been clearly defined. For those NETs that demonstrate uptake to a diagnostic scan with ${ }^{123}$ I-MIBG or ${ }^{111}$ In-octreotide, therapy with radionuclides such as ${ }^{131} \mathrm{I}$-MIBG or ${ }^{111} \mathrm{In} /{ }^{90}$ Y-octreotide or other isotopes, presents a further evolving therapeutic modality.
\end{abstract}

European Journal of Endocrinology 151 15-27

\section{Introduction}

Malignant neuroendocrine tumours (NETs) constitute a rare and heterogeneous group of tumours including the neuroendocrine adrenal, as well as endocrine islets within glandular tissue (thyroid or pancreatic) and cells dispersed between exocrine cells, such as endocrine cells of the digestive and respiratory tracts, known as carcinoid tumours (1). Carcinoid tumours have traditionally been classified further according to the anatomical site of origin: foregut, midgut and hindgut (2). Within these subgroups the biological and clinical characteristics of the tumours vary considerably (3). NETs can either be sporadic or occur as part of familial syndromes, mainly multiple endocrine neoplasia (MEN) I and II, Von Hippel Lindau (VHL) syndrome and neurofibromatosis (NF)-I, and have multipotent secretory capacities producing distinct clinical syndromes (4-6). In addition, they can express neuroamine uptake mechanisms and/or specific receptors, such as somatostatin (SS) receptors, at the cell membrane, which can be of great value in their localization and treatment (7). The majority of NETs exhibit an indolent growth pattern (well-differentiated NETs), but a substantial number may metastasize, mainly to the liver; a minority of NETs may be very aggressive and demonstrate a highly malignant course (poorly-differentiated NETs) (8). Scintigraphy with ${ }^{111}$ In-octreotide has become an imaging modality of major importance in the evaluation of gastro-enteropancreatic (GEP), islet cell or carcinoid tumours, whereas scintigraphy with ${ }^{123}$ I-MIBG (meta-iodobenzylguanidine) is of greater value in the evaluation of chromaffin cell tumours (phaeochromocytomas and paragangliomas); scintigraphy with both ${ }^{111}$ In-octreotide and ${ }^{123}$ I-MIBG can also be used for medullary thyroid carcinoma (MTC) $(8,9)$. The use of these radiolabelled substances (radionuclides) is associated with a $67-100 \%$ sensitivity and may also identify other clinically unsuspected lesions and thus contribute 
to the overall staging of the disease $(8-10)$. Further imaging with computed tomography/magnetic resonance imaging (CT/MRI) and/or ultrasonography will be required for the precise localization of NETs and for monitoring their response to treatment (11). Although positron emission tomography (PET) imaging is currently evolving as an alternative imaging method it is not at present widely available, and its precise role remains to be determined (12).

The initial management of NETs is surgical excision of the primary tumour (13). In the majority of patients who are not cured by surgery alone, medical therapy with agents such as somatostatin analogues and/or interferon- $\alpha$ is used to control the symptoms associated with specific humoral syndromes and may prevent tumour growth (14). Chemotherapy is currently mainly reserved for patients with aggressive, recurrent and/or progressive disease (8), whereas treatment directed against liver metastases is used in patients with excessive hepatic tumour load and uncontrollable symptoms (15-18). Specific therapy with radionuclides such as MIBG or somatostatin analogues appears promising for tumours which show diagnostic uptake, and has been increasingly used over the last decade. Further more experimental treatments, either alone or in combination with the existing ones, are under development $(19,20)$.

This review will focus on the ability of radionuclides to identify NETs, will identify recent advances in other imaging modalities, and will explore the rationale of using therapy with radiolabelled substances. The various radionuclides used, the results of observational and other prospective trials, their potential side-effects, and the integration of this treatment with other forms of treatment, will be discussed.

\section{Radionuclide and radiological imaging}

\section{Amine uptake and peptide receptor expression and visualization}

The demonstration of amine-uptake mechanisms and the high density of peptide receptors on NETs and their metastases has been used for both the diagnosis and monitoring of these tumours using techniques with radionuclides $(21-23)$. Radionuclides provide a diagnostic modality in which radiolabelled amines or peptide analogues, after binding to suitable ligands, are utilized for the identification and localization of NETs (9). NETs and their metastases can be visualized in vivo using a $\gamma$-camera after the injection of various radionuclides, such as ${ }^{123} \mathrm{I}$-MIBG and ${ }^{111} \mathrm{In}$-pentetreotide (24-26). In addition, other small peptide receptors that are expressed in cell membranes of NET tissues include vasointestinal peptide (VIP), bombesin, cholecystokinin (CCK), gastrin and/or substance P (19, 20, $27,28)$, and these can also be used as markers for in vivo tumour visualization $(19,20,27)$.
Scintigraphy with meta-iodobenzylguanidine (123 I-MIBG) MIBG is a guanidine derivative that exploits the type 1 uptake mechanism at the cell membrane, and is stored within intracellular storage vesicles (29, 30). MIBG localizes to adrenomedullary tumours, hyperplastic adrenal medulla and the healthy adrenal medulla; in addition, carcinoid tumours and MTC can also accumulate MIBG (31). The efficiency of ${ }^{123} \mathrm{I}-$ MIBG is excellent for the visualization of intra-adrenal (phaeochromocytomas) and extra-adrenal (paragangliomas) chromaffin cell tumours, and can identify multiple tumours in patients with familial syndromes, showing a diagnostic sensitivity and specificity of around $90 \%(24,31,32)$. Occasionally, ${ }^{123}$ I-MIBGnegative malignant chromaffin cell tumors may demonstrate uptake to ${ }^{111}$ In-octreotide $(33,34)$. Scintigraphy with ${ }^{123} \mathrm{I}-\mathrm{MIBG}$ can also be used for the selection of patients for therapeutic MIBG based on a positive diagnostic scan; its sensitivity has been reported to be enhanced by the pre-imaging administration of 'cold' MIBG, although this remains controversial (35).

Scintigraphy with ${ }^{111}$ In-octreotide Somatostatin (SS) is a widely expressed peptide which mostly acts as an inhibitory factor after binding to specific somatostatin receptors (36). Because of its short half-life (1-2 min), many SS long-acting analogues, with a half life of $1.5-2 \mathrm{~h}$ and thus prolonged biological activity, have been synthesized, among which octreotide and lanreotide are the ones most commonly used $(37,38)$. SS analogues bind with high affinity to SS receptor subtypes 2 and 5 which are found in a large variety of NETs, adenocarcinomas, inflammatory and immune cells $(18,39)$. The most commonly-used SS analogue, octreotide, was initially conjugated with DTPA (diethylene-triamine-penta-acetic acid), but more recently to DOTA $(1,4,7,10$-tetraazacyclododecane-1,4,7, 10-tetra-acetic acid) as a way of coupling SS analogues with various radioisotopes, mainly ${ }^{111} \mathrm{In}$ $(21,26,40)$. Scintigraphy with ${ }^{111}$ In-octreotide is superior to ${ }^{111}$ In-lanreotide and has a detection rate of $67-100 \%$ for all NETs; it can therefore be used for the diagnosis, staging and follow-up of patients with NETs $(9,41,42) .{ }^{111}$ In-DTPA-Tyr ${ }^{3}$-octreotate, a newly synthesized SS analogue, demonstrated higher tumour uptake than ${ }^{111}$ In-DTPA-Tyr ${ }^{3}$-octreotide whereas kidney uptake remained similar $(21,43,44)$. More recently, ${ }^{68} \mathrm{Ga}$ coupled to octreotide or ${ }^{64} \mathrm{Cu}-$ TETA-octreotide have been used as tracers for PET imaging, and have demonstrated more lesions than ${ }^{111} \mathrm{In}-$ octreotide in patients with NETs $(45,46)$. Alternatively, scanning with radiolabelled VIP has been shown to be equally sensitive to ${ }^{111}$ In-octreotide in patients with GEP tumours $(28,47-49)$; in addition, other small peptide receptors expressed on the cell membranes of NET cells, such as those for bombesin, CCK, gastrin and/or substance $\mathrm{P}(47,50)$, can also be used for 
in vivo tumour visualization (50). Finally, the superimposition of ${ }^{111}$ In-octreotide SPECT (single photon emission computerized tomography) with CT/MRI slices (anatomical-functional image fusion) has shown improved localization and characterization of NETs (51) (Fig. 1). However, at present, in spite of efforts aimed at developing more specific radioligands, ${ }^{111} \mathrm{In}-$ octreotide remains the radionuclide of first choice for the imaging of NETs $(27,49)$.

\section{Recent advances in other imaging modalities in the diagnosis of various NETs}

Cross-sectional imaging techniques are used in the localization and staging of NETs and in assessing respone to therapy. Many different imaging methods have been advocated, particularly for the localization of GEP tumours, which reflects the difficulties encountered in demonstrating these tumours which are usually small and inconspicuous. Direct comparison of imaging techniques is limited, as the differences in diagnostic performance often reflect techniques at different stages of development, and comparative series are usually small.

Recent advances in ultrasound Endoscopic ultrasound (EUS), with colour doppler, has a high sensitivity $(79-100 \%)$ for the detection of small lesions in the pancreas $(52,53)$. Pancreatic endocrine tumours demonstrate abundant colour doppler signal, which may have pulsatile and/or continuous wave patterns (54). This marked vascularity may help to characterize

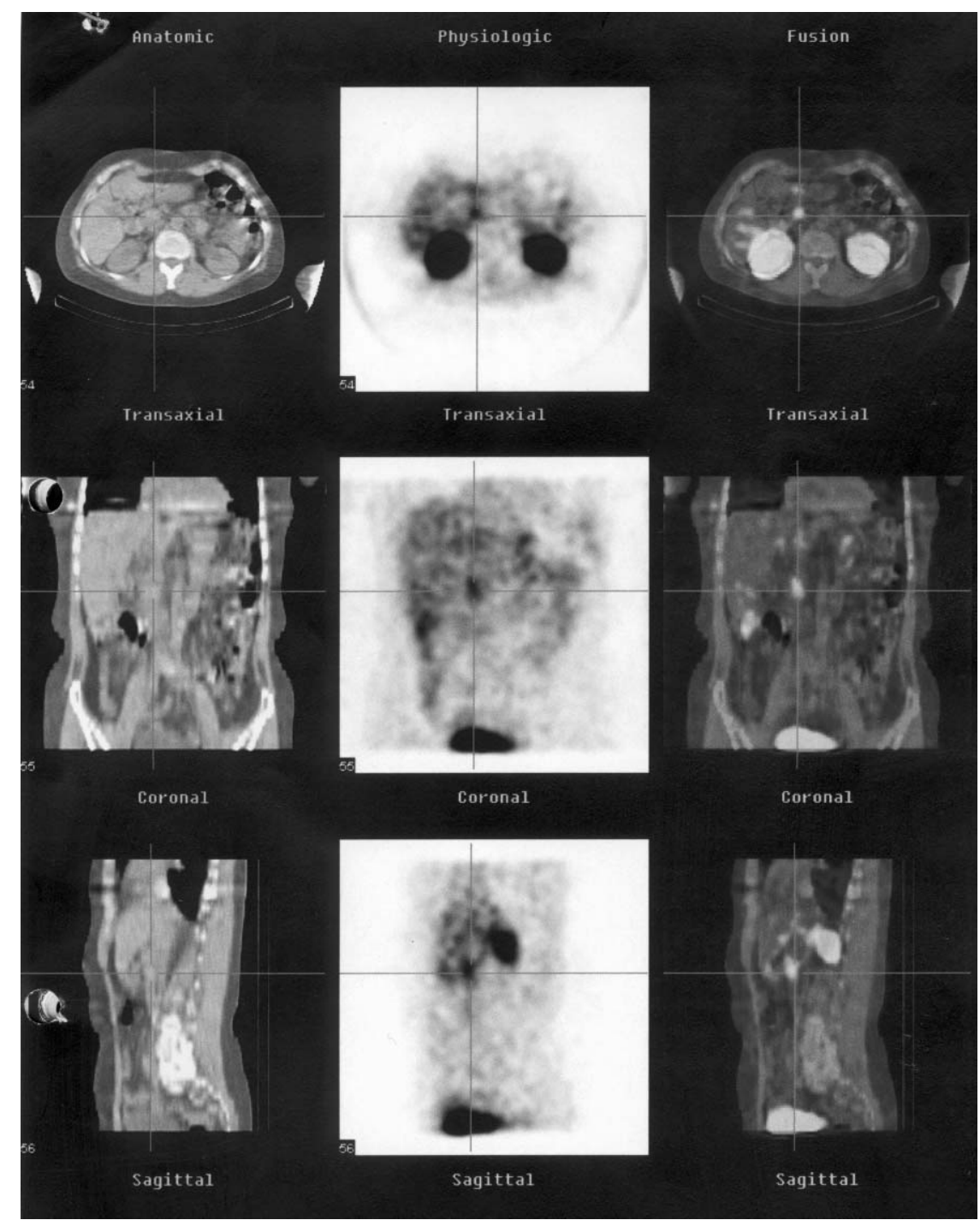

Figure 1 Lesion in head of pancreas. This is an indium octreotide scan of a probable islet cell tumour located in the head of the pancreas with SPECT-CT fusion. The left column shows a CT scan, the second column the ${ }^{111}$ In-octreotide scan, while the third column shows the superimposition of the CT and the radionuclide scans, identifying the 'hotspot' in the pancreas. (Courtesy of Prof. K E Britton.) 
a lesion (e.g. as a non-functioning neuroendocrine lesion) as many pancreatic adenocarcinomas are of relatively low vascularity (55). The advantages of EUS include its sensitivity in the localization of small and multiple tumours (particularly in the pancreatic head, which may be difficult to palpate at surgery), the detection of tumours in the duodenal wall, and local lymph node enlargement; however, it is less sensitive in detecting disease in the tail of the pancreas $(52,53)$. The use of ultrasound 'microbubble' contrast medium has been shown to help in the characterization of pancreatic lesions. Following injection of contrast medium, there is usually marked homogeneous enhancement throughout NETs, closely resembling the CT enhancement pattern (55-57). Contrast-enhanced ultrasound has also been shown to improve the detection of liver metastases on transabdominal ultrasound by increasing the number of lesions seen, although its specific use in neuroendocrine liver metastases has not been reported to date $(58)$.

Intraoperative ultrasound (IOUS) This technique, which has similar advantages to EUS, may improve the sensitivity for identifying small lesions in the head and multiple lesions to up to $97 \%$ (59). It is a useful addition to surgical palpation, particularly in small tumours such as insulinomas. IOUS has the advantage, over EUS, of being able also to assess the liver. However, it is not as sensitive as surgical palpation in detecting extra-pancreatic lesions and increases the time and complexity of operation. It also requires the time of an experienced radiologist during the operation.

Endo-anal ultrasound Hind-gut carcinoids of the rectum may be small and superficial, with no evidence of metastatic disease. In cases where disease is confined to the rectum, minimally invasive local resection, such as transanal endoscopic microsurgery (TEM), is the treatment of choice mainly for stage T1 (tumour confined to mucosa and submucosa) and T2 (invasion of muscularis propria) disease, with no evidence of extension beyond the muscularis (60-62). Endo-anal ultrasound demonstrates the lesion as a homogeneously hypoechoic submucosal mass (63). Endo-anal ultrasound may demonstrate invasion beyond the muscularis layer (stage T3) and invasion into adjacent structures (stage T4) (61). In these cases, open resection is required.

Advances in CT imaging of NETs The advent of multi-detector CT (MDCT) has allowed further improvements in image resolution. The advantages of the technique include: (i) the ability to perform very rapid $\mathrm{CT}$, thus reducing movement artifacts; (ii) bolus-tracking to produce precise timing of the scan, in order to allow very accurate arterial phase images to be acquired; (iii) the ability to retrospectively reconstruct the images to a very narrow slice thickness (i.e. after scanning the patient) and thereby improve the resolution; (iv) the ability to perform high resolution reformatted images in any anatomical plane.

Many of these features are of particular importance in the imaging of NETs, which are often small and very vascular and therefore need excellent arterial phase images. In the chest, endobronchial carcinoids may be imaged using thin sections, which may then be reformatted in the coronal plane for optimal demonstration of the bronchial tree. The reformatted display may also be helpful in surgical planning (64). In the abdomen, most NETs are hypervascular and will be best seen in the arterial phase after injection of intravenous contrast medium. However, in some cases, portal venous phase imaging best demonstrates the tumour. Thus, dual-phase imaging, commencing scanning at about 30 and $70 \mathrm{~s}$ following intravenous injection of contrast medium is recommended to optimize the sensitivity of the technique, both for the primary tumour and for the demonstration of liver metastases (6568). The sensitivity for the detection of pancreatic insulinomas using dual-phase MDCT was 94\% in one recent series; in the same publicaton, dual-phase MDCT without thin sections had a sensitivity of $57 \%$ while in patients who underwent non-helical CT, the sensitivity was only 29\%; an overall diagnostic sensitivity of $100 \%$ for combined dual-phase thin section MDCT and endoscopic ultrasound has been reported (69), although others have shown a sensitivity of $63 \%$ for the detection of pancreatic insulinomas using multi-phase helical CT or MDCT alone (70).

Recently, 41 patients with hyperfunctioning phaeochromocytomas were treated with a percutaneous ethanol injection using CT-guidance, with disappearance of the lesion in 31 patients and shrinkage or complete necrosis in 10 patients, with follow-up over 23-54 months (71). Although this is an interesting new technique it is not widely practised at present and needs confirmation from studies including a larger number of patients with more prolonged follow-up.

Enteroclysis Small bowel enteroclysis is an established technique for the diagnosis of small bowel midgut carcinoids (72). The technique involves a tube being passed into the distal duodenum through which a large volume of contrast (usually barium) is introduced. However, by providing only the luminal view of the small bowel it may miss the primary tumour, disease in the mesenteric nodes, secondary mesenteric masses and/or liver metastases $(73,74)$. CT enteroclysis (CT-E) combines the diagnostic information available from both small bowel enteroclysis and the cross-sectional display provided by CT, thus demonstrating luminal, mural and extraluminal abnormalities in the small bowel. MDCT has enabled marked improvements in CT-E, due to the multiplanar reformatting. This is a relatively new development, being used in specialized centres, for the investigation of 
small bowel lesions, and may have a role in the future in identifying the primary site of mid-gut carcinoids (75-77).

CT fusion imaging The 'Hawkeye' system combines the advantages of SPECT functional imaging with the anatomical resolution of CT (Fig. 1). The combined SPECT/CT device allows hybrid imaging using both SS scintigraphy and low-dose CT, providing well-localized functional information. This has two main advantages: first, functionally active areas can be co-located with possible sites of disease visible on CT, and secondly, physiological sites of tracer uptake can be clearly identified and thus discounted as sites of disease. One recent study using this technique demonstrated an increase in specificity for identifying NETs when compared with SPECT or CT alone; furthermore, $28 \%$ of patients had an alteration in treatment plan due to the image fusion results (51).

New developments in MRI Marked improvements in MRI technology have occurred over the past decade, resulting in improved diagnostic performance in the detection of NETs. In the chest, marked enhancement of bronchial carcinoids may create diagnostic difficulty on $\mathrm{CT}$, as the appearance may mimic a pulmonary varix or pulmonary artery aneurysm, and a small vascular lesion may be overlooked or interpreted as a normal vessel (64). When a pulmonary lesion is suspected but cannot be seen on CT, MRI may play a role in localization. Bronchial carcinoids are of high signal intensity on T2-weighted and STIR images ('short tau inversion recovery', a T2-weighted sequence with fat suppression), allowing distinction between a small mass and the pulmonary vasculature of the central and middle third of the lung (78). In GEP lesions, a sensitivity of $94 \%$ for pancreatic lesions, but less for extra-pancreatic lesions, has been reported, with the best conspicuity of tumour usually on the T1 fat-saturated sequence (Fig. 2) (79, 80). MRI may also demonstrate the primary tumour mass in mid-gut carcinoids. In the largest reported series, the primary mass was identified in 8 of 12 patients with a gastrointestinal carcinoid (81). The best sequence for demonstrating the primary tumour was the post-gadolinium T1-weighted fat-suppressed image. MRI enteroclysis is also being developed, but currently this technique does not perform as well as CT-E and has not been used in the localization of primary mid-gut carcinoids (82). It may be used in the future, as the technique develops.

The liver-specific contrast agent, mangafodipir-trisodium (Mn-DPDP), may have a role in improved detection of neuroendocrine liver metastases. This is an intravenous contrast medium that is taken up by normal hepatocytes resulting in T1-brightening of the liver. Metastatic lesions are seen as low signal lesions against the bright liver parenchyma (Fig. 3). This technique is currently under investigation (83).
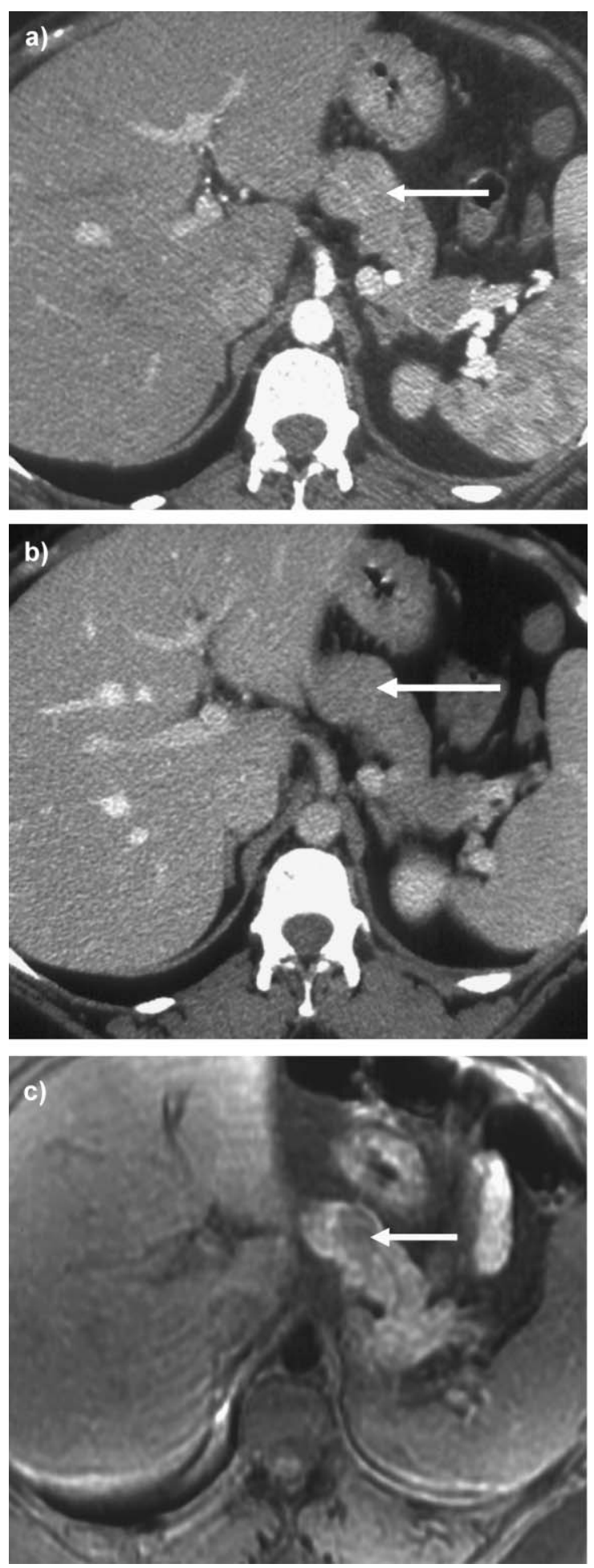

Figure 2 Pancreatic insulinoma. CT images in the arterial phase (a) and the portal venous phase (b) do not clearly demonstrate the lesion in the pancreas (white arrows) in this case. However, T1-weighted MRI with fat saturation (c) clearly demonstrates the lesion (arrow) in the body of the pancreas, which has a low signal intensity against the high signal intensity of the normal pancreas. 
In hind-gut carcinoids of the rectum, MRI may have a role in local staging of the primary mass, where endoanal ultrasound suggests extension of disease beyond the muscularis. MRI staging of rectal adenocarcinoma is now well established (84), but there are few data on MRI staging of carcinoid tumours at this site.

Positron emission tomography (PET) Positron emission tomography utilizes the ability of radiolabelled tracers to be taken-up by certain tumours, and thus selectively assesses the function of different metabolic pathways of the specific tissue (85). It combines high sensitivity and reasonable resolution, and offers the ability to perform whole body scans $(86,87)$; ${ }^{18}$ F-labelled deoxyglucose (FDG) was the first tracer used, reflecting the increased glucose uptake in malignant tumours $(86,87)$. However, since NETs are mostly well-differentiated and slow-growing tumours, they have a low metabolic rate and cannot be visualized efficiently with this tracer $(12,86)$. Increased FDG uptake can be seen in less-differentiated NETs without SS receptors; in such cases the sensitivity of FDG-PET is clearly higher than that of scintigraphy
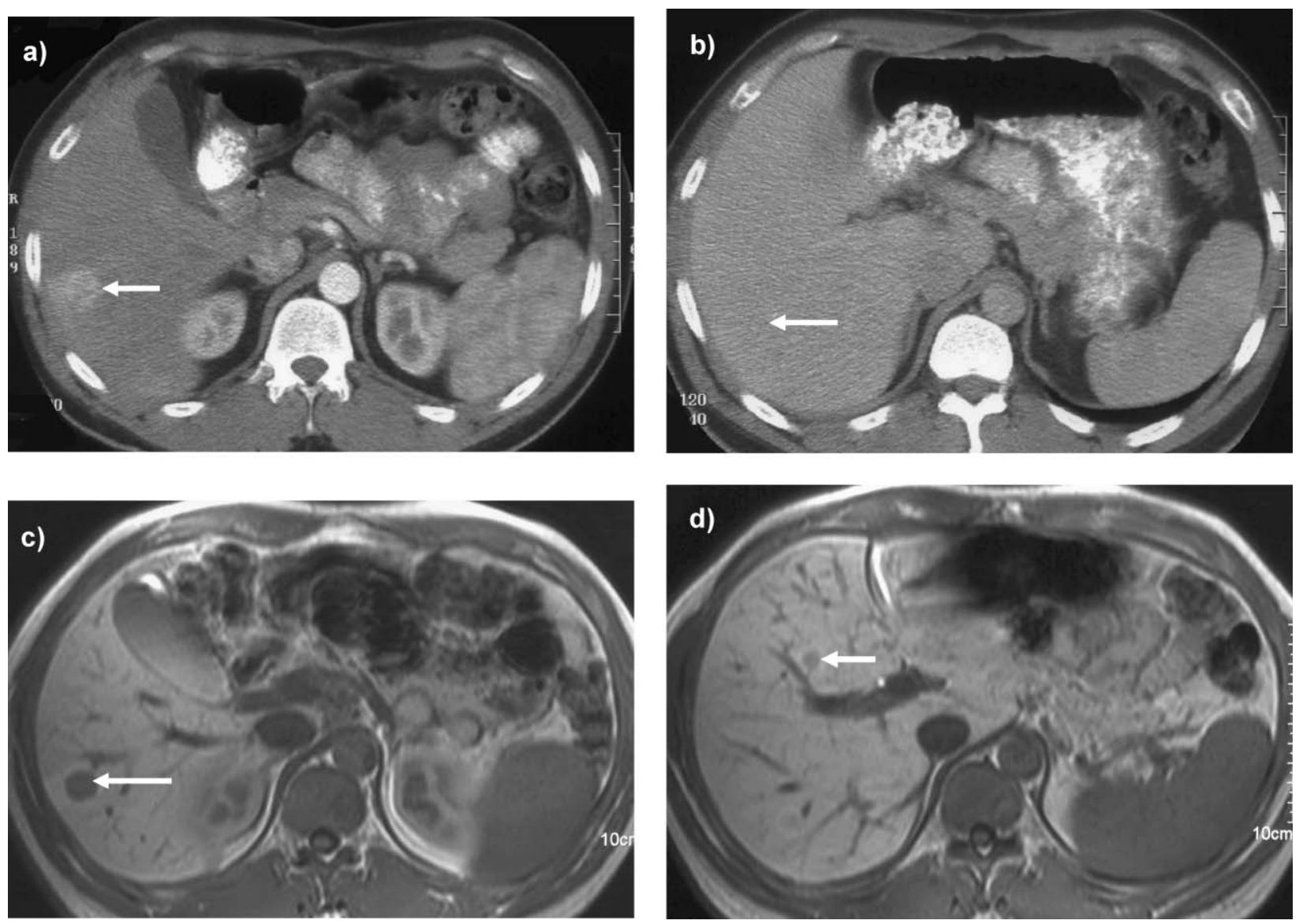

Figure 3 Neuroendocrine liver metastases. On CT, a liver lesion is enhanced on the arterial phase image (a), but the size and contour of the lesion is poorly defined (arrow). The lesion is not conspicuous on the portal venous phase image (b). On MRI with Mn-DPDP, the lesion is clearly demonstrated with a well-defined margin (c) and, in addition, a second lesion is demonstrated in (d), which could not be seen on CT or on pre-contrast MRI.

with ${ }^{111}$ In-pentetreotide (86). The metabolic pathway synthesizing 5-hydroxytryptamine (5-HT) from 5hydroxytryptophan (5-HTP) occurs in carcinoids and other NETs and can thus also be used for PET-imaging $(85,88,89) ;{ }^{11} \mathrm{C}-5$-HTP is specifically trapped by serotonin-producing tumours and this can be further enhanced by the concomitant administration of carbidopa (88). PET imaging using ${ }^{11} \mathrm{C}$-5-HTP has been shown to be superior to CT scanning in diagnosing GEP tumours and monitoring their response to therapy; for poorly-differentiated tumours FDG-PET can be used instead (86). Since scintigraphy with ${ }^{111}$ In-octreotide fails to visualize $10-20 \%$ of GEP tumours, PET may prove to be useful in certain cases, although this needs to be formally assessed by a prospective trial (90).

\section{Basic concepts involved in the application of radionuclide therapy to NETs}

Coupling a radioisotope to a molecule which would specifically bind to tumour cells could, in theory, deliver

www.eje.org 
an effective radiation dose to the tumour without damage to non-tumour tissues $(25,91)$. Tumour heterogeneity may cause incomplete responses unless the radiation delivered can kill the nearby tumour cells that are target-negative; this depends on the cross-fire from the radioisotope localized in or on the target-positive tumour cells $(23,92)$. Radioiodine for treatment of thyroid disorders has been the best example of a radionuclide targeting agent with a high target-tonon-target ratio, rapid clearance of the unbound radioisotope, and a long residence time in the target (23). With the introduction of ${ }^{131} \mathrm{I}-\mathrm{MIBG}$ and, more recently, octreotide labelled with several radioisotopes, the field of treatment with radionuclides has been extended to a wide range of NETs $(9,23,93)$. The patients' responses to therapy are best evaluated using uniform criteria and are usually divided into symptomatic, hormonal and tumour responses according to World Health Organisation criteria (94).

\section{${ }^{131}$ I-MIBG therapy for malignant NETs}

Before using ${ }^{131}$ I-MIBG therapy a diagnostic ${ }^{123}$ I-MIBG scan is necessary to substantiate the avidity of tumour cells for the radionuclides (95). Imaging is performed after all medication known to interfere with MIBG uptake has been discontinued for at least one week prior to diagnostic scintigraphy or treatment (29, 94, 95). There is always free ${ }^{131} \mathrm{I}$ present (albeit only a very small amount) in the administered material, so to minimize thyroidal ${ }^{131} \mathrm{I}$ uptake, potassium iodide $120-150 \mathrm{mg} /$ day is given starting 2 days before and continued for 8-21 days post-therapy $(29,94,95)$.

Results of treatment Despite variations in selection criteria, dosimetry and therapeutic protocols, sufficient experience has now accumulated to confirm the efficacy of treatment with ${ }^{131}$ I-MIBG $(24,31,94-96)$. Most centres have used between 100 and $300 \mathrm{mCi}$ (3.7 and $11.1 \mathrm{GBq}){ }^{131} \mathrm{I}-\mathrm{MIBG}$ per treatment; ${ }^{131} \mathrm{I}-$ MIBG therapy is repeated, usually at 6-month intervals, until either complete remission is observed on either a diagnostic ${ }^{123}$ I-MIBG or no uptake is seen on a therapeutic ${ }^{131}$ I-MIBG scan, or the total dose is thought to be limiting in terms of toxicity, usually around $1-1.2 \mathrm{Ci}(30,94,97)$.

Malignant carcinoid tumours The worldwide cumulative experience using ${ }^{131}$ I-MIBG treatment in 52 patients with metastatic carcinoid disease was reported in 1994; an objective tumour response was recorded in $15 \%$ with a symptomatic response in $65 \%$ of the patients (98). Since then, the results in another 47 patients have been reported demonstrating a $60 \%$ symptomatic and $12.5 \%$ hormonal response respectively, but with minimal reduction in tumour mass $(94,96,99,100)$.

Malignant islet cell tumours Very few cases of malignant islet cell tumours treated with ${ }^{131}$ I-MIBG have been reported, reflecting the relatively poor ${ }^{123} \mathrm{I}-\mathrm{MIBG}$ uptake of these tumours $(94,96)$. Scintigraphy with ${ }^{111}$ In-pentetreotide is more sensitive than scintigraphy with ${ }^{123} \mathrm{I}-\mathrm{MIBG}$, and it is expected that treatment with ${ }^{90}$ Y-labelled SS analogues will be applicable to a larger population of patients with NETs, particularly islet cell tumours, and will also target the same lesions identified by ${ }^{131}$ I-MIBG; the results of phase II trials are now becoming available (101).

Malignant MTC The worldwide cumulative experience was reported in 1991 and 1994 for 18 and 22 patients respectively; an objective tumour response was documented in approximately $30 \%$ of patients with a symptomatic response in 50\% $(98,102-104)$. Since then, a further 4 reports including 17 patients have appeared demonstrating a complete response in one patient plus two partial responses, while no response was obtained in the rest of the patients (31, 94, 99). Although tumour disappearance was exceptional, there was considerable improvement in symptoms with improved quality of life in the majority, with beneficial effects on hormonal and tumour control in a substantial number of patients $(94,97)$.

\section{${ }^{131}$ I-MIBG therapy for malignant chromaffin-cell} tumours The results of treatment with ${ }^{131} \mathrm{I}-\mathrm{MIBG}$ in 106 evaluable patients with malignant phaeochromocytomas was originally presented in 1991 (94, 98, 105). Since then the cumulative reported therapeutic response of ${ }^{131} \mathrm{I}$-MIBG therapy in patients with phaeochromocytomas and paragangliomas has been extensively reviewed $(30,95)$. In the majority of patients clinically symptomatic improvement relating to catecholamine hypersecretion was observed; a biochemical response was almost always associated with a symptomatic response. An overall tumour response (partial tumour response or stabilization of the disease) was obtained in $58 \%$ of the patients $(30,95,96)$. The therapeutic response reported is quite heterogeneous, as it depends on several factors including tumour size and extension, ${ }^{131}$ I-MIBG tumour uptake and retention $(30,95)$.

Toxicity Haematological toxicity is the main significant side-effect of ${ }^{131}$ I-MIBG therapy (94). Severe myelosuppression is mainly seen in patients with widespread bone metastases and diffuse bone marrow involvement, and in patients heavily pretreated with chemotherapy $(94,106)$. Similarly, patients with widespread hepatic metastases should be observed carefully following ${ }^{131}$ I-MIBG therapy as transient hepatic failure can occur $(31,94)$.

Future prospects The integration of ${ }^{131}$ I-MIBG therapy with chemotherapy can be attempted to avoid the emergence of resistant clones which do not take up MIBG $(24,37,107)$. However, in a recent prospective 
trial combining MIBG with chemotherapy, while an additive anti-tumour effect was demonstrated, pretreatment with MIBG increased toxicity which curtailed the proposed chemotherapy protocol (30). Treatment with ${ }^{131}$ I-MIBG in combination with myeloablative chemotherapy and haematopoietic stem-cell rescue has been shown to be feasible, and useful responses with accepted toxicity were obtained in children with relapsed or progressive neuroblastomas (30). This could also be used in adult patients with malignant chromaffin cell or NETs. It may also be possible that predosing with non-radiolabelled MIBG might improve ${ }^{131}$ I-MIBG tumour targeting and enhance its therapeutic effect in patients with other NETs that accumulate MIBG $(35,108)$. Although a number of observational studies have demonstrated that ${ }^{131} \mathrm{I}$ MIBG therapy has a significant anti-tumour effect, controlled studies are needed to clarify patient selection, radiation dosimetry, size and frequency of ${ }^{131}$ I-MIBG doses, and the integration of ${ }^{131}$ I-MIBG with other therapeutic modalities (30).

\section{Treatment with radiolabelled somatostatin analogues}

Mapping of the presence of various peptide receptors on the cell membrane by peptide receptor scintigraphy has become an evolving procedure which is non-invasive and without major side-effects, and an easy-to-perform method in the selection of patients for therapy with radionuclides $(20,25)$.

Radionuclide therapy with ${ }^{111}$ In octreotide ${ }^{111}$ In emits mainly $\gamma$-irradiation, Auger and conversion electrons, and exerts an anti-proliferative effect in malignant tumours if their principal target, cellular DNA, is within the particle range $(44,109,110)$. Thirty endstage patients with NETs, including 20 patients with GEP tumours, were treated with $\left[{ }^{111} \mathrm{In}\right.$-DTPA]-octreotide (25). Six patients demonstrated a partial shrinkage of the tumour, whereas in another 8 patients there was stabilization of their disease; there was a tendency towards better results in patients with high tumour uptake (25); similar results have also been described in another 10 patients although an impairment in spermatogenesis was noted $(44,111)$. A further 27 patients were treated with ${ }^{111} \mathrm{In}$-pentetreotide, using two doses $(180 \mathrm{mCi})$, with $62 \%$ and $81 \%$ obtaining a symptomatic and hormonal response respectively (112). Objective partial responses occurred in $2(8 \%)$ patients and significant tumour necrosis in 7 (27\%), without any major side effect, while the median survival was 18 months compared with the 6 months expected (112). However, recent studies have shown that the response may not be sustained over time, probably due to the preferential survival of resistant clones, and that its efficacy in large tumours and end-stage patients is limited (113). Therefore, it was suggested that ${ }^{111}$ In-octreotide should be given either in combination with $\beta$-emitters, or alone but only to eradicate micrometastases (44). Toxicity of the treatment was generally low with $100 \mathrm{GBq}$ being the maximal tolerable dose (44).

\section{Radionuclide therapy with ${ }^{90}$ Y-octreotide/DOT}

ATOC Radionuclides emitting $\beta$-irradiation have greater therapeutic potential since the particles they emit have sufficient energy to cause cell damage, and they deliver higher radiation doses to a larger part of the tumour without penetrating very far into the surrounding tissue $(23,25,114)$. The same SS analogue ( $\mathrm{Tyr}^{3}$-octreotide) used for diagnosis has been coupled to a bifunctional chelating agent (DOTA) for the complexing of ${ }^{90} \mathrm{Y}$, a pure energetic $\beta$-emitter $(19,43,44$, $114,115)$. The complex ${ }^{90}$ Y-DOTA-D-Phe ${ }^{1}-$ Tyr $^{3}$ octreotide ( ${ }^{90}$ Y-SMT487, OctreoTher) (Novartis, Basel, Switzerland) is well suited for internal radiotherapy and, as it is mainly eliminated from the kidneys, it is administered with a concomitant intravenous infusion of amino-acids which reduce renal radioactivity without affecting the radionuclide uptake by the tumour $(22,25,114,116)$. There is also experience using ${ }^{90}$ Y-DOTATOC, a compound which appears to be similar to OctreoTher (117-119); of 10 patients with metastatic NETs treated with ${ }^{90}$ Y-DOTATOC, 6 reported an improvement in tumour growth, hormonal secretion and symptoms, with minimal side-effects, while the others showed stable disease (117). In total, 29 patients have been treated with ${ }^{90}$ Y-DOTATOC: 6 obtained a remission while 20 had disease stabilization (118, 119). In a phase II non-randomized study, 37 patients with GEP tumours, the majority of whom had resistant and progressive disease, were treated with 4 intravenous injections of ${ }^{90}$ Y-DOTA-D-Phe ${ }^{1}$ $\mathrm{Tyr}^{3}$-octreotide, up to a total of $6000 \mathrm{MBq} / \mathrm{m}^{2}$ (120). An objective tumour response of $24 \%$ (36\% for pancreatic tumours) was noted, without serious toxicity; there was also a suggestion of a more favourable outcome in the treated patients (120). Similar to the results in patients who received ${ }^{131}$ I-MIBG treatment, the main predictor of the outcome of therapy was the extent of the disease and the total tumour load (94). More recently, the results of 87 patients with NETs ( $57 \%$ had GEP and 16\% MTC) treated with a cumulative activity ranging from $7.4-20.3 \mathrm{GBq}$ were presented; a tumour response was obtained in $28 \%(5 \%$ complete response) with no major adverse effects up to a dose of $5.55 \mathrm{GBq} /$ cycle (121). Other studies also involving the administration of DOTA-D-Phe ${ }^{1}-\mathrm{Tyr}^{3}-$ octreotide in patients with NETs have mainly demonstrated a partial tumour response, while a considerable number showed disease stabilization (122); an overall partial response rate of around $20 \%$ has been documented in all these studies with a maximum cumulative dose being relatively less than the maximum tolerable dose (44). A Novartis-sponsored phase II study is 
currently ongoing to test the efficacy of OctreoTher in patients with a variety of disseminated NETs; it is hoped that the detailed results will be published soon $(44,114)$.

Radionuclide therapy with ${ }^{90}$ Y Ianreotide Lanreotide shows a slightly different affinity to octreotide for SS receptors (122). Following a 25\% regression of liver metastases and substantial symptomatic improvement in a patient with a malignant gastrinoma after four infusions of $1 \mathrm{GBq}{ }^{90} \mathrm{Y}$ lanreotide, a phase IIa Multicentre Analysis of a Universal Receptor Imaging and Treatment Initiative (MAURITIUS) European study was organized, in which 39 patients with GEP tumours and 34 carcinoid tumours were included (123). After 2 cycles of ${ }^{90}$ Y-DOTA-lanreotide the treatment was discontinued in the case of progressive disease, otherwise another 2 cycles were given. Over a 3-year follow-up period, $20.5 \%$ of patients showed regression while $43.6 \%$ maintained stable disease (123). However, as ${ }^{90}$ Y-DOTA-D-Phe ${ }^{1}-\mathrm{Tyr}^{3}$-octreotide shows higher tumour uptake in patients with NETs lesions compared with lanreotide, although this may be associated with increased haematological toxicity, the former appears at present to offer the more effective treatment (20). A few patients with MTC have also received ${ }^{111} \mathrm{In}$-octreotide or ${ }^{90}$ Y-lanreotide in the MAURITIUS trial $(113,123)$ : although this was a not homogeneous group of patients, the initial results were encouraging, supporting further prospective studies for the use of this form of therapy in patients with advanced MTC disease.

Radionuclide therapy with $\left[^{177}\right.$ Lu-DOTA Tyr $\left.^{3}\right]$ octreotate In order to overcome the limitations of administering tumoricidal doses of radiotherapy to non-octreotide avid lesions, and the lack of uptake to certain areas due to tumour heterogeneity, several $\beta$-emitters, in addition to ${ }^{90} \mathrm{Y}$, such as ${ }^{153} \mathrm{Sm},{ }^{177} \mathrm{Lu}$ and ${ }^{186} \mathrm{Re}$, are also under consideration, usually in combination with the newest SS analogue, Tyr ${ }^{3}$-octreotate, which exhibits the highest affinity for SS receptor type $2(19,22,44) .{ }^{177} \mathrm{Lu}$-DOTA-Tyr ${ }^{3}$-octreotate shows very high tumour uptake with a very good ratio of tumour-to-kidney uptake and can also be imaged by a $\gamma$-camera, thus suggesting an ideal compound for therapy with radionuclides $(20,44)$. Radiotherapy with ${ }^{177}$ Lu-DOTA-Tyr ${ }^{3}$-octreotate has recently been reported in 18 patients with a variety of progressive NETs, with $39 \%$ of patients showing a partial remission with minimal adverse effects $(44,124)$. It has also been suggested that in patients with tumours of different sizes, including small metastases, the administration of combinations of different radionuclides, e.g. ${ }^{90} \mathrm{Y}$ which is optimal for larger tumours and ${ }^{177} \mathrm{Lu}$ which is optimal for smaller tumours, coupled to octreotide and/or octreotate, may be particularly useful $(19,20$, 124).
Radioembolization NETs show a particular predisposition for hepatic metastases which receive most of their blood supply from the hepatic artery, and hepatic administration of $\beta$-emitting radionuclides presents an attractive approach to deliver therapeutic focal irradiation $(125,126)$. Preliminary studies have shown that complications are low and, if the tumour pattern is nodular with some hypervascularity, beneficial results may develop both clinically and in terms of tumour burden $(125,126)$.

Future prospects For CCK-B receptor positive tumours, such as MTC, radiolabelled minigastrin analogues are currently under development (19). Multi-receptor tumour targeting using the combination of bombesin and neuropeptide Y (NPY) analogues is promising for both scintigraphy and therapy of tumours bearing such receptors (19). Peptides that can antagonize tumour angiogenesis by binding to $\alpha_{\nu} \beta_{3}$ receptors of newlyformed blood vessels can also be used for both scintigraphy and treatment with radionuclides (127). To increase further tumoral uptake, hybrid peptides combining uptake via both SS receptors subtype 2 and $\alpha_{\nu} \beta_{3}$ receptors have been constructed. Immune system activation for the control of micrometastatic disease may also be required to achieve complete control and eventual cure.

\section{Multidisciplinary approach}

The increasing number of investigatory procedures and therapeutic options for both the diagnosis and treatment of malignant NETs is best dealt with by a multidisciplinary team. As patients with malignant NETs are rare, optimum management should be performed in centres with relevant experience and expertise. In order to evaluate the results of current management, establish guidelines and develop new therapeutic trials, multicentre collaborative protocols should be encouraged. This will limit the number of variations in therapy protocols to permit the interpretation of pooled data, particularly by establishing uniform entry, response and adverse reaction criteria, dose intervals and escalation of administered activity, and absorbed radiation dose.

\section{Conclusions}

The localization of small NETs, assessing the extent of malignant lesions and monitoring response to therapy, remains a radiological challenge. Technological advances in cross-sectional imaging methods such as refinements in endoscopic ultrasound, multi-detector CT and MRI sequences have undoubtedly improved their accuracy. There is also promise being shown by newer ultrasound and MRI contrast agents in the staging of the disease. However, there is still a dearth of studies that produce valid results in comparing these 
techniques and the choice of the most appropriate technique will depend on a constellation of several factors such as local expertise, availability and cost. Scintigraphy with ${ }^{123} \mathrm{I}-\mathrm{MIBG}$ and ${ }^{111} \mathrm{In}$-pentetreotide is routinely used for staging, often revealing clinically unsuspected lesions, and can affect the management of NETs that demonstrate uptake to these radionuclides. When considering therapy with radionuclides, the best radioligand should be carefully investigated. For all radionuclides used for therapy, long-term and survival statistics are not yet available and only partial tumour responses have been obtained using ${ }^{131} \mathrm{I}$ MIBG and ${ }^{111}$ In-octreotide. Initial results using ${ }^{90}$ Y-DOTA-lanreotide as well as ${ }^{90}{ }^{9}$-DOTA-D-Phe ${ }^{1}$ $\mathrm{Tyr}^{3}$-octreotide and/or ${ }^{177}$ Lu-DOTA-Tyr ${ }^{3}$-octreotate have indicated the possible clinical potential of radionuclides receptor-targeted radiotherapy, but side-effect profile analyses are not as yet fully available. In most cases receptor-mediated radiotherapy has been used in patients with an excessive tumour load and/or refractory disease, but it may also be the case that this form of treatment could be considered in patients with receptor-positive tumours to eradicate small amounts of residual disease or the presence of occult metastases. In order to minimize resistance and increase the efficacy of the treatment, further multicentre collaborative protocols with newly evolving treatments should be encouraged. Combination therapy with both ${ }^{131}$ I-MIBG and ${ }^{90}$ Y-labelled somatostatin analogues or ${ }^{111} \mathrm{In}-,{ }^{90} \mathrm{Y}$ - and ${ }^{177} \mathrm{Lu}$-labelled SS analogues remains an attractive theoretical option. It may be hoped that the efficacy of internal radiotherapy will be improved by co-administration of chemotherapeutic drugs whose radiosensitizing properties may be synergistic with that of irradiation.

\section{References}

1 Capella C, Heitz PU, Hofler H, Solcia E \& Kloppel G. Revised classification of neuroendocrine tumours of the lung, pancreas and gut. Virchows Archives $1995 \mathbf{4 2 5} 547-560$.

2 Solcia E, Kloppel G \& Sobin LH. Histological Typing of Endocrine Tumours, edn 2, pp 38-74. Springer Verlag, Berlin \& Heidelberg, World Health Organisation, 2000.

3 Caplin ME, Buscombe JR, Hilson AJ, Jones AL, Watkinson AF \& Burroughs AK. Carcinoid tumour. Lancet 1998352 799-805.

4 Oberg K. Carcinoid tumors: molecular genetics, tumor biology, and update of diagnosis and treatment. Current Opinion in Oncology $2002 \mathbf{1 4} 38-45$.

5 Bravo EL. Pheochromocytoma. Cardiology Reviews 200210 $44-50$.

6 Giuffrida D \& Gharib H. Current diagnosis and management of medullary thyroid carcinoma. Annals of Oncology 19989 695-701.

7 Faiss S, Scherubl H, Riecken EO \& Wiedenmann B. Drug therapy in metastatic neuroendocrine tumors of the gastroenteropancreatic system. Recent Results in Cancer Research 1996142 193-207.

8 Kaltsas G, Mukherjee JJ, Plowman PN \& Grossman AB. The role of chemotherapy in the nonsurgical management of malignant neuroendocrine tumours. Clinical Endocrinology $2001 \mathbf{5 5}$ 575-587.
9 Kaltsas GA, Mukherjee JJ \& Grossman AB. The value of radiolabelled MIBG and octreotide in the diagnosis and management of neuroendocrine tumours. Annals of Oncology 200112 (Suppl 2) $\mathrm{S} 47-\mathrm{S} 50$.

10 Isidori AM, Kaltsas G, Frajese V, Kola B, Whitelocke RA, Plowman PN et al. Ocular metastases secondary to carcinoid tumors: the utility of imaging with $\left[{ }^{123} \mathrm{I}\right]$ meta-iodobenzylguanidine and $\left[{ }^{111} \mathrm{In}\right] \mathrm{DTPA}$ pentetreotide. Journal of Clinical Endocrinology and Metabolism 200287 1627-1633.

11 Ricke J, Klose KJ, Mignon M, Oberg K \& Wiedenmann B. Standardisation of imaging in neuroendocrine tumours: results of a European delphi process. European Journal of Radiology 2001 37 8-17.

12 Eriksson B, Bergstrom M, Orlefors H, Sundin A, Oberg K \& Langstrom B. Use of PET in neuroendocrine tumors. In vivo applications and in vitro studies. Quarterly Journal of Nuclear Medicine $2000 \mathbf{4 4} 68-76$.

13 Skogseid B. Nonsurgical treatment of advanced malignant neuroendocrine pancreatic tumors and midgut carcinoids. World Journal of Surgery 200125 700-703.

14 Arnold R \& Frank M. Control of growth in neuroendocrine gastro-enteropancreatic tumours. Digestion 199657 (Suppl 1) 69-71.

15 Hellman P, Ladjevardi S, Skogseid B, Akerstrom G \& Elvin A. Radiofrequency tissue ablation using cooled tip for liver metastases of endocrine tumors. World Journal of Surgery 200226 1052-1056.

16 Lamberts SW, Bakker WH, Reubi JC \& Krenning EP. Somatostatin receptor imaging in vivo localization of tumors with a radiolabeled somatostatin analog. Journal of Steroid Biochemistry and Molecular Biology 199037 1079-1082.

17 Reubi JC, Krenning E, Lamberts SW \& Kvols L. Somatostatin receptors in malignant tissues. Journal of Steroid Biochemistry and Molecular Biology 199037 1073-1077.

18 Reubi JC, Laissue J, Krenning E \& Lamberts SW. Somatostatin receptors in human cancer: incidence, characteristics, functional correlates and clinical implications. Journal of Steroid Biochemistry and Molecular Biology 199243 27-35.

19 de Jong M, Kwekkeboom D, Valkema R \& Krenning EP. Radiolabelled peptides for tumour therapy: current status and future directions. Plenary lecture at the EANM 2002. European Journal of Nuclear Medicine and Molecular Imaging 200330 463-469.

20 Weiner RE \& Thakur ML. Radiolabeled peptides in the diagnosis and therapy of oncological diseases. Applied Radiation and Isotopes $200257749-763$.

21 Kwekkeboom DJ, Hoff AM, Lamberts SW, Oei HY \& Krenning EP. Somatostatin analogue scintigraphy. A simple and sensitive method for the in vivo visualization of Merkel cell tumors and their metastases. Archives of Dermatology 1992128 818-821.

22 Krenning EP, Bakker WH, Breeman WA, Koper JW, Kooij PP, Ausema L et al. Localisation of endocrine-related tumours with radioiodinated analogue of somatostatin. Lancet $1989 \mathbf{1}$ 242-244.

23 Wiseman GA \& Kvols LK. Therapy of neuroendocrine tumors with radiolabeled MIBG and somatostatin analogues. Seminars in Nuclear Medicine $199525272-278$.

24 Shapiro B. Ten years of experience with MIBG applications and the potential of new radiolabeled peptides: a personal overview and concluding remarks. Quarterly Journal of Nuclear Medicine $199539150-155$.

25 Krenning EP, de Jong M, Kooij PP, Breeman WA, Bakker WH, de Herder WW et al. Radiolabelled somatostatin analogue(s) for peptide receptor scintigraphy and radionuclide therapy. Annals of Oncology 199910 (Suppl 2) S23-S29.

26 Krenning EP, Kwekkeboom DJ, de Jong M, Visser TJ, Reubi JC, Bakker WH et al. Essentials of peptide receptor scintigraphy with emphasis on the somatostatin analog octreotide. Seminars in Oncology 199421 6-14. 
27 Kwekkeboom D, Krenning EP \& de Jong M. Peptide receptor imaging and therapy. Journal of Nuclear Medicine $2000 \mathbf{4 1}$ 1704-1713.

28 Virgolini I, Raderer M, Kurtaran A, Angelberger P, Banyai S, Yang Q et al. Vasoactive intestinal peptide-receptor imaging for the localization of intestinal adenocarcinomas and endocrine tumors. New England Journal of Medicine 1994331 1116-1121.

29 Troncone L \& Rufini V. ${ }^{131}$ I-MIBG therapy of neural crest tumours (review). Anticancer Research 199717 1823-1831.

30 Kaltsas G, Mukherjee JJ, Foley R, Britton K \& Grossman A. Treatment of metastatic pheochromocytoma and paraganglioma with ${ }^{131}$ I-meta-iodobenzylguanidine (MIBG). Endocrinologist 200313 $1-13$.

31 Troncone L \& Rufini V. Nuclear medicine therapy of pheochromocytoma and paraganglioma. Quarterly Journal of Nuclear Medicine $199943344-355$.

32 Shapiro B, Sisson JC, Shulkin BL, Gross MD \& Zempel S. The current status of meta-iodobenzylguanidine and related agents for the diagnosis of neuro-endocrine tumors. Quarterly Journal of Nuclear Medicine $1995393-8$.

33 Krempf M, Lumbroso J, Mornex R, Brendel AJ, Wemeau JL, Delisle MJ et al. Treatment of malignant pheochromocytoma with $\left[{ }^{131} \mathrm{I}\right]$ metaiodobenzylguanidine: a French multicenter study. Journal of Nuclear and Biological Medicine 199135 284-287.

34 Krempf M, Lumbroso J, Mornex R, Brendel AJ, Wemeau JL, Delisle MJ et al. Use of $\mathrm{m}-\left[{ }^{131} \mathrm{I}\right]$ iodobenzylguanidine in the treatment of malignant pheochromocytoma. Journal of Clinical Endocrinology and Metabolism 199172 455-461.

35 Taal BG, Hoefnagel C, Boot H, Valdes OR \& Rutgers M. Improved effect of ${ }^{131}$ I-MIBG treatment by predosing with non-radiolabeled MIBG in carcinoid patients, and studies in xenografted mice. Annals of Oncology 200011 1437-1443.

36 Reubi JC, Maurer R, von Werder K, Torhorst J, Klijn JG \& Lamberts SW. Somatostatin receptors in human endocrine tumors. Cancer Research $198747551-558$.

37 Lamberts SW, van der Lely AJ, de Herder WW \& Hofland LJ. Somatostatin analogs: future directions. Metabolism $1996 \mathbf{4 5}$ 104-106.

38 Hofland LJ \& Lamberts SW. Somatostatin analogs and receptors. Diagnostic and therapeutic applications. Cancer Treatment and Research 199789 365-382.

39 Reubi JC, Kvols L, Krenning E \& Lamberts SW. Distribution of somatostatin receptors in normal and tumor tissue. Metabolism $19903978-81$.

40 Reubi JC, Lamberts SJ \& Krenning EP. Receptor imaging of human diseases using radiolabeled peptides. Journal of Receptor and Signal Transduction Research 199515 379-392.

41 Krenning EP, Kwekkeboom DJ, Bakker WH, Breeman WA, Kooij PP, Oei HY et al. Somatostatin receptor scintigraphy with ${ }^{111}$ In-DTPA-D-Phe $\left.{ }^{1}\right]$ - and $\left[{ }^{123}{ }^{1}-T_{y r}{ }^{3}\right]$-octreotide: the Rotterdam experience with more than 1000 patients. European Journal of Nuclear Medicine 199320 716-731.

42 Krenning EP, Valkema R, Kooij PP, Breeman WA, Bakker WH, deHerder WW et al. Scintigraphy and radionuclide therapy with [indium-111-labelled-diethyl triamine penta-acetic acid-D$\mathrm{Phe}^{1}$ ]-octreotide. Italian Journal of Gastroenterology and Hepatology 199931 (Suppl 2) S219-S223.

43 Kwekkeboom DJ \& Krenning EP. Somatostatin receptor imaging. In Advances in oncology: the expanding role of octreotide. Eds SWJ Lamberts \& L Dogliotti. BioScientifica: Bristol, 2002 .

44 de Jong M, Valkema R, Jamar F, Kvols LK, Kwekkeboom DJ, Breeman WA et al. Somatostatin receptor-targeted radionuclide therapy of tumors: preclinical and clinical findings. Seminars in Nuclear Medicine 200232 133-140.

45 Hofland LJ \& Lamberts SW. Somatostatin receptor subtype expression in human tumors. Annals of Oncology 200112 (Suppl 2) S31-S36.

46 Anderson CJ, Dehdashti F, Cutler PD, Schwarz SW, Laforest R, Bass LA et al. ${ }^{64} \mathrm{Cu}$-TETA-octreotide as a PET imaging agent for patients with neuroendocrine tumors. Journal of Nuclear Medicine. 200142 213-221.

47 Reubi JC, Laissue J, Waser B, Horisberger U \& Schaer JC. Expression of somatostatin receptors in normal, inflamed, and neoplastic human gastrointestinal tissues. Annals of the New York Academy of Sciences 1994733 122-137.

48 Reubi JC. Neuropeptide receptors in health and disease: the molecular basis for in vivo imaging. Journal of Nuclear Medicine 1995 36 1825-1835.

49 Bombardieri E, Maccauro M, Castellani MR, Chiti A, Procopio G, Bajetta E et al. Radioisotopic imaging of neuroendocrine tumours. Which radiopharmaceutical and which diagnostic procedure? Minerva Endocrinologica 200126 197-213.

50 de Herder WW, van der Lely AJ \& Lamberts SW. Somatostatin analogue treatment of neuroendocrine tumours. Postgraduate Medical Journal 199672 403-408.

51 Pfannenberg AC, Eschmann SM, Horger M, Lamberts R, Vonthein R, Claussen CD et al. Benefit of anatomical-functional image fusion in the diagnostic work-up of neuroendocrine neoplasms. European Journal of Nuclear Medicine and Molecular Imaging $200330835-843$.

52 Rosch T, Lightdale CJ, Botet JF, Boyce GA, Sivak MV Jr, Yasuda K et al. Localization of pancreatic endocrine tumors by endoscopic ultrasonography. New England Journal of Medicine $1992 \mathbf{3 2 6}$ $1721-1726$.

53 Fein J \& Gerdes H. Localization of islet cell tumors by endoscopic ultrasonography. Gastroenterology 1992103 711-712.

54 Ueno N, Tomiyama T, Tano S, Wada S, Aizawa T \& Kimura K. Utility of endoscopic ultrasonography with color Doppler function for the diagnosis of islet cell tumor. American Journal of Gastroenterology $199691772-776$.

55 Ozawa Y, Numata K, Tanaka K, Ueno N, Kiba T, Hara K et al. Contrast-enhanced sonography of small pancreatic mass lesions. Journal of Ultrasound in Medicine 200221 983-991.

56 Nagase M, Furuse J, Ishii H \& Yoshino M. Evaluation of contrast enhancement patterns in pancreatic tumors by coded harmonic sonographic imaging with a microbubble contrast agent. Journal of Ultrasound in Medicine 200322 789-795.

57 Oshikawa O, Tanaka S, Ioka T, Nakaizumi A, Hamada Y \& Mitani T. Dynamic sonography of pancreatic tumors: comparison with dynamic CT. American Journal of Roentgenology 2002 178 1133-1137.

58 Esteban JM, Molla MA, Tomas C \& Maldonado L. Improved detection of liver metastases with contrast-enhanced wideband harmonic imaging: comparison with CT findings. European Journal of Ultrasound 200215 119-126.

59 Grant CS. Surgical aspects of hyperinsulinemic hypoglycemia. Endocrinology and Metabolism Clinics of North America 199928 $533-554$

60 Maeda K, Maruta M, Utsumi T, Sato H, Masumori K \& Matsumoto M. Minimally invasive surgery for carcinoid tumors in the rectum. Biomedicine and Pharmacotherapy 2002 56 (Suppl 1) 222s-226s.

61 Schindl M, Niederle B, Hafner M, Teleky B, Langle F, Kaserer K et al. Stage-dependent therapy of rectal carcinoid tumors. World Journal of Surgery 199822 628-633.

62 Oshitani N, Hamasaki N, Sawa Y, Hara J, Nakamura S, Matsumoto T et al. Endoscopic resection of small rectal carcinoid tumours using an aspiration method with a transparent overcap. Journal of International Medical Research 200028 241-246.

63 Matsumoto T, Iida M, Suekane H, Tominaga M, Yao T \& Fujishima M. Endoscopic ultrasonography in rectal carcinoid tumors: contribution to selection of therapy. Gastrointestinal Endoscopy 199137 539-542.

64 Jeung MY, Gasser B, Gangi A, Charneau D, Ducroq X, Kessler R et al. Bronchial carcinoid tumors of the thorax: spectrum of radiologic findings. Radiographics 200222 351-365.

65 Stafford-Johnson DB, Francis IR, Eckhauser FE, Knol JA \& Chang AE. Dual-phase helical CT of nonfunctioning islet cell 
tumors. Journal of Computer Assisted Tomography 199822 335-339.

66 Van Hoe L, Gryspeerdt S, Marchal G, Baert AL \& Mertens L. Helical CT for the preoperative localization of islet cell tumors of the pancreas: value of arterial and parenchymal phase images. American Journal of Roentgenology $1995 \mathbf{1 6 5}$ 1437-1439.

67 Chung MJ, Choi BI, Han JK, Chung JW, Han MC \& Bae SH. Functioning islet cell tumor of the pancreas. Localization with dynamic spiral CT. Acta Radiologica 199738 135-138.

68 Ichikawa T, Peterson MS, Federle MP, Baron RL, Haradome H, Kawamori Y et al. Islet cell tumor of the pancreas: biphasic CT versus MR imaging in tumor detection. Radiology $2000 \mathbf{2 1 6}$ $163-171$

69 Gouya H, Vignaux O, Augui J, Dousset B, Palazzo L, Louvel A et al. CT, endoscopic sonography, and a combined protocol for preoperative evaluation of pancreatic insulinomas. American Journal of Roentgenology $2003 \mathbf{1 8 1} 987-992$.

70 Fidler JL, Fletcher JG, Reading CC, Andrews JC, Thompson GB, Grant CS et al. Preoperative detection of pancreatic insulinomas on multiphasic helical CT. American Journal of Roentgenology $2003 \mathbf{1 8 1} 775-780$

71 Wang P, Zuo C, Oian Z, Tian J, Ren F \& Zhou D. Computerized tomography guided percutaneous ethanol injection for the treatment of hyperfunctioning pheochromocytoma. Journal of Urology $20031701132-1134$.

72 Gasparaitis AE \& MacEneaney P. Enteroclysis and computed tomography enteroclysis. Gastroenterology Clinics of North America 200231 715-730.

73 Woodard PK, Feldman JM, Paine SS \& Baker ME. Midgut carcinoid tumors: CT findings and biochemical profiles. Journal of Computer Assisted Tomography 199519 400-405.

74 Sugimoto E, Lorelius LE, Eriksson B \& Oberg K. Midgut carcinoid tumours. CT appearance. Acta Radiologica $199536367-371$.

75 Horton KM \& Fishman EK. The current status of multidetector row CT and three-dimensional imaging of the small bowel. Radiologic Clinics of North America 200341 199-212.

76 Maglinte DD, Bender GN, Heitkamp DE, Lappas JC \& Kelvin FM. Multidetector-row helical CT enteroclysis. Radiologic Clinics of North America $200341249-262$.

77 Orjollet-Lecoanet C, Menard Y, Martins A, Crombe-Ternamian A, Cotton F \& Valette PJ. CT enteroclysis for detection of small bowel tumors. Journal de Radiologie $2000 \mathbf{8 1}$ 618-627.

78 Doppman JL, Pass HI, Nieman LK, Findling JW, Dwyer AJ, Feuerstein IM et al. Detection of ACTH-producing bronchial carcinoid tumors: MR imaging vs CT. American Journal of Roentgenology $199115639-43$.

79 Owen NJ, Sohaib SA, Peppercorn PD, Monson JP, Grossman AB, Besser GM et al. MRI of pancreatic neuroendocrine tumours. British Journal of Radiology 200174 968-973.

80 Thoeni RF, Mueller-Lisse UG, Chan R, Do NK \& Shyn PB. Detection of small, functional islet cell tumors in the pancreas: selection of MR imaging sequences for optimal sensitivity. Radiology 2000214 483-490.

81 Bader TR, Semelka RC, Chiu VC, Armao DM \& Woosley JT. MRI of carcinoid tumors: spectrum of appearances in the gastrointestinal tract and liver. Journal of Magnetic Resonance Imaging 2001 $14261-269$.

82 Schmidt S, Lepori D, Meuwly JY, Duvoisin B, Meuli R, Michetti P et al. Prospective comparison of MR enteroclysis with multidetector spiral-CT enteroclysis: interobserver agreement and sensitivity by means of 'sign-by-sign' correlation. European Radiology 200313 1303-1311.

83 Wang C. Mangafodipir trisodium (MnDPDP)-enhanced magnetic resonance imaging of the liver and pancreas. Acta Radiologica. Supplementum $1998 \mathbf{4 1 5} 1-31$.

84 Maier A \& Fuchsjager M. Preoperative staging of rectal cancer. European Journal of Radiology 200347 89-97.
85 Eriksson B, Orlefors H, Sundin A, Westlin JE, Bergstrom M, Langstrom B et al. PET in neuroendocrine tumors. Nordick Medicine $1998113308-312$.

86 Eriksson B, Bergstrom M, Sundin A, Juhlin C, Orlefors H, Oberg K et al. The role of PET in localization of neuroendocrine and adrenocortical tumors. Annals of the New York Academy of Sciences $2002970159-169$.

87 Eriksson B, Orlefors H, Sundin A, Skogseid B, Langstrom B, Bergstrom $\mathrm{M}$ et al. Positron emission tomography in neuroendocrine tumours. Italian Journal of Gastroenterology and Hepatology 199931 (Suppl 2) S167-S171.

88 Orlefors H, Sundin A, Ahlstrom H, Bjurling P, Bergstrom M, Lilja A et al. Positron emission tomography with 5-hydroxytryptophan in neuroendocrine tumors. Journal of Clinical Oncology $1998162534-2541$

89 Sundin A, Eriksson B, Bergstrom M, Bjurling P, Lindner KJ, Oberg $\mathrm{K}$ et al. Demonstration of $\left[{ }^{11} \mathrm{C}\right]$ 5-hydroxy-L-tryptophan uptake and decarboxylation in carcinoid tumors by specific positioning labeling in positron emission tomography. Nuclear Medicine and Biology 200027 33-41.

90 Bombardieri E, Aliberti G, de Graaf C, Pauwels E \& Crippa F. Positron emission tomography (PET) and other nuclear medicine modalities in staging gastrointestinal cancer. Seminars in Surgical Oncology 200120 134-146.

91 Kaltsas G, Stefanidou Z, Papadogias D \& Grossman A. Treatment of advanced neuroendocrine tumours with the radiolabelled somatostatin analogue octreotide. Hormones 2002 1 149-156.

92 de Jong M, Bakker WH, Krenning EP, Breeman WA, van der Pluijm ME, Bernard BF et al. Yttrium-90 and indium-111 labelling, receptor binding and biodistribution of [DOTA0,D-Phe ${ }^{1}$, $\mathrm{Tyr}^{3}$ ]octreotide, a promising somatostatin analogue for radionuclide therapy. European Journal of Nuclear Medicine 199724 368-371.

93 Taal BG, Hoefnagel CA, Valdes Olmos RA \& Boot H. Combined diagnostic imaging with ${ }^{131}$ I-metaiodobenzylguanidine and ${ }^{111}$ In-pentetreotide in carcinoid tumours. European Journal of Cancer 1996 32A 1924-1932.

94 Mukherjee JJ, Kaltsas GA, Islam N, Plowman PN, Foley R, Hikmat I et al. Treatment of metastatic carcinoid tumours, phaeochromocytoma, paraganglioma and medullary carcinoma of the thyroid with $\left({ }^{131}\right)$ I-meta-iodobenzylguanidine $\left({ }^{131}\right) \mathrm{I}$ mIBG. Clinical Endocrinology 200155 47-60.

95 Loh KC, Fitzgerald PA, Matthay KK, Yeo PP \& Price DC. The treatment of malignant pheochromocytoma with iodine-131 metaiodobenzylguanidine ( $\left.{ }^{131} \mathrm{I}-\mathrm{MIBG}\right)$ : a comprehensive review of 116 reported patients. Journal of Endocrinological Investigation $199720648-658$.

96 Bomanji JB, Wong W, Gaze MN, Cassoni A, Waddington W, Solano J et al. Treatment of neuroendocrine tumours in adults with ${ }^{131}$ I-MIBG therapy. Clinical Oncology (Royal College of Radiologists) 200315 193-198.

97 Chatal JF, Le Bodic MF, Kraeber-Bodere F, Rousseau C \& Resche I. Nuclear medicine applications for neuroendocrine tumors. World Journal of Surgery 200024 1285-1289.

98 Hoefnagel CA. Metaiodobenzylguanidine and somatostatin in oncology: role in the management of neural crest tumours. European Journal of Nuclear Medicine 199421 561-581.

99 Castellani MR, Chiti A, Seregni E \& Bombardieri E. Role of ${ }^{131} \mathrm{I}$ metaiodobenzylguanidine (MIBG) in the treatment of neuroendocrine tumours. Experience of the National Cancer Institute of Milan. Quarterly Journal of Nuclear Medicine 2000 44 77-87.

100 Taal BG, Hoefnagel CA, Valdes Olmos RA, Boot H \& Beijnen JH. Palliative effect of metaiodobenzylguanidine in metastatic carcinoid tumors. Journal of Clinical Oncology $1996 \mathbf{1 4} 1829-1838$.

101 Kaltsas G, Korbonits M, Heintz E, Mukherjee JJ, Jenkins PJ, Chew SL et al. Comparison of somatostatin analog and metaiodobenzylguanidine radionuclides in the diagnosis and localization of advanced neuroendocrine tumors. Journal of Clinical Endocrinology and Metabolism 200186 895-902. 
102 Ahlman H, Wangberg B, Jansson S, Friman S, Olausson M, Tylen U et al. Interventional treatment of gastrointestinal neuroendocrine tumours. Digestion 200062 (Suppl 1) 59-68.

103 Hoefnagel CA, Delprat CC \& Valdes Olmos RA. Role of $\left[{ }^{131} \mathrm{I}\right]$ metaiodobenzylguanidine therapy in medullary thyroid carcinoma. Journal of Nuclear and Biological Medicine 199135 $334-336$.

104 Troncone L, Rufini V, Maussier ML, Valenza V, Daidone MS, Luzi $S$ et al. The role of $\left[{ }^{131} \mathrm{I}\right]$ metaiodobenzylguanidine in the treatment of medullary thyroid carcinoma: results in five cases. Journal of Nuclear and Biological Medicine 199135 $327-331$.

105 Hoefnagel CA, Schornagel J \& Valdes Olmos RA. $\left[{ }^{131} \mathrm{I}\right]$ Metaiodobenzylguanidine therapy of malignant pheochromocytoma: interference of medication. Journal of Nuclear and Biological Medicine $199135308-312$.

106 Sisson JC, Shapiro B, Shulkin BL, Urba S, Zempel S \& Spaulding S. Treatment of malignant pheochromocytomas with ${ }^{131}$-I metaiodobenzylguanidine and chemotherapy. American Journal of Clinical Oncology 199922 364-370.

107 Hoefnagel CA, Clarke SE, Fischer M, Chatal JF, Lewington VJ, Nilsson S et al. Radionuclide therapy practice and facilities in Europe. EANM Radionuclide Therapy Committee. European Journal of Nuclear Medicine 199926 277-282.

108 Hoefnagel CA, Taal BG, Sivro F, Boot H \& Valdes Olmos RA. Enhancement of ${ }^{131}$ I-MIBG uptake in carcinoid tumours by administration of unlabelled MIBG. Nuclear Medicine Communications 200021 755-761.

109 Balon HR, Goldsmith SJ, Siegel BA, Silberstein EB, Krenning EP, Lang $\mathrm{O}$ et al. Procedure guideline for somatostatin receptor scintigraphy with $\left({ }^{111}\right)$ In-pentetreotide. Journal of Nuclear Medicine $2001421134-1138$.

110 Fjalling M, Andersson P, Forssell-Aronsson E, Gretarsdottir J, Johansson V, Tisell LE et al. Systemic radionuclide therapy using indium-111-DTPA-D-Phe ${ }^{1}$-octreotide in midgut carcinoid syndrome. Journal of Nuclear Medicine 199637 1519-1521.

111 Valkema R, de Jong M, Bakker WH, Breeman WA, Kooij PP, Lugtenburg PJ et al. Phase I study of peptide receptor radionuclide therapy with [In-DTPA] octreotide: the Rotterdam experience. Seminars in Nuclear Medicine 200232 110-122.

112 Anthony LB, Woltering EA, Espenan GD, Cronin MD, Maloney TJ \& McCarthy KE. Indium-111-pentetreotide prolongs survival in gastroenteropancreatic malignancies. Seminars in Nuclear Medicine 200232 123-132.

113 Buscombe JR, Caplin ME \& Hilson AJ. Long-term efficacy of highactivity ${ }^{111}$ In-pentetreotide therapy in patients with disseminated neuroendocrine tumors. Journal of Nuclear Medicine $2003 \mathbf{4 4} 1-6$.

114 Smith MC, Liu J, Chen T, Schran H, Yeh CM, Jamar F et al. OctreoTher: ongoing early clinical development of a somatostatin-receptor-targeted radionuclide antineoplastic therapy. Digestion 200062 (Suppl 1) 69-72.
115 de Jong M, Boerman OC \& Krenning EP. Peptides and monoclonal antibodies in oncology: an introduction. Cancer Biotherapy and Radiopharmaceuticals $2003 \mathbf{1 8} 591-592$.

116 van Eijck CH, de Jong M, Breeman WA, Slooter GD, Marquet RL \& Krenning EP. Somatostatin receptor imaging and therapy of pancreatic endocrine tumors. Annals of Oncology $1999 \mathbf{1 0}$ (Suppl 4) 177-181.

117 Otte A, Mueller-Brand J, Dellas S, Nitzsche EU, Herrmann R \& Maecke HR. Yttrium-90-labelled somatostatin-analogue for cancer treatment. Lancet 1998351 417-418.

118 Otte A, Herrmann R, Heppeler A, Behe M, Jermann E, Powell P et al. Yttrium-90 DOTATOC: first clinical results. European Journal of Nuclear Medicine 199926 1439-1447.

119 Otte A, Herrmann R, Macke HR \& Muller-Brand J. Yttrium 90 DOTATOC: a new somatostatin analog for cancer therapy of neuroendocrine tumors. Schweizerische Rundschau fur Medizin Praxis 199988 1263-1268.

120 Waldherr C, Pless M, Maecke HR, Haldemann A \& MuellerBrand J. The clinical value of $\left[{ }^{90}\right.$ Y-DOTA $]-D-P^{1}-\mathrm{Tyr}^{3}$-octreotide $\left({ }^{90}\right.$ Y-DOTATOC) in the treatment of neuroendocrine tumours: a clinical phase II study. Annals of Oncology $200112941-945$.

121 Paganelli G, Bodei L, Handkiewicz JD, Rocca P, Papi S, Lopera SM et al. ${ }^{90}$ Y-DOTA-D-Phe ${ }^{1}$-Try ${ }^{3}$-octreotide in therapy of neuroendocrine malignancies. Biopolymers 200266 393-398.

122 Virgolini I, Traub T, Novotny C, Leimer M, Fuger B, Li SR et al. Experience with indium-111 and yttrium-90-labeled somatostatin analogs. Current Pharmaceutical Design 20028 1781-1807.

123 Virgolini I, Britton K, Buscombe J, Moncayo R, Paganelli G \& Riva P. In- and Y-DOTA-lanreotide: results and implications of the MAURITIUS trial. Seminars in Nuclear Medicine 200232 $148-155$

124 Kwekkeboom DJ, Bakker WH, Kooij PP, Konijnenberg MW, Srinivasan A, Erion JL et al. ${ }^{177}$ Lu-DOTAOTyr $\left.{ }^{3}\right]$ octreotate: comparison with [ ${ }^{111}$ In-DTPAo]octreotide in patients. European Journal of Nuclear Medicine 200128 1319-1325.

125 Herba MJ \& Thirlwell MP. Radioembolization for hepatic metastases. Seminars in Oncology 200229 152-159.

126 Andrews JC, Walker SC, Ackermann RJ, Cotton LA, Ensminger WD \& Shapiro B. Hepatic radioembolization with yttrium-90 containing glass microspheres: preliminary results and clinical follow-up. Journal of Nuclear Medicine 199435 $1637-1644$.

127 van Hagen PM, Breeman WA, Bernard HF, Schaar M, Mooij CM, Srinivasan A et al. Evaluation of a radiolabelled cyclic DTPA-RGD analogue for tumour imaging and radionuclide therapy. International Journal of Cancer 200090 186-198.

Received 30 December 2003

Accepted 30 March 2004 